\title{
(Marked 2-1) A Circularly Polarized Planar Antenna on Flexible Substrate for Ultra-wideband High-band Applications
}

\author{
Koji Fujita ${ }^{l}$, Kuniaki Yoshitomi ${ }^{2}$, Keiji Yoshida ${ }^{l}$, and Haruichi Kanaya ${ }^{l}$ \\ ${ }^{I}$ Graduate School of Information Science and Electrical Engineering, Kyushu University, \\ 744 Motooka, Fukuoka, 819-0395, Japan \\ ${ }^{2}$ EJUST Center, Kyushu University, \\ 744 Motooka, Fukuoka, 819-0395, Japan \\ Phone: $+81-92-802-3746$ \\ FAX: $+81-92-802-3720$ \\ E-mail:kanaya@ed.kyushu-u.ac.jp
}

\begin{abstract}
This paper presents the design of a circularly polarized slot antenna on a flexible substrate for ultra-wideband (UWB) high-band applications, as well as the behavior of the antenna near a human body. We used two slots that were crossed perpendicularly to obtain a circularly polarized wave. We realized wideband impedance matching to optimize the lengths and widths of the antenna slots and substrate. The impedance bandwidth of proposed antenna is $5.60 \mathrm{GHz}$ from 7.11 to $12.71 \mathrm{GHz}$, and the antenna size is $16 \mathrm{~mm} \times 16.3 \mathrm{~mm} \times 0.254 \mathrm{~mm}$.
\end{abstract}

Keywords: Slot antenna, ultra-wideband (UWB), flexible, circularly polarized antenna.

\section{INTRODUCTION}

In 2002, the Federal Communications Commission (FCC) in the United States released regulations for Ultra wide band (UWB) technology, and a variety of UWB systems such as sensor networks, body area networks, and radar systems have been developed [1, 2]. There are many reports on planar UWB antennas, for example, U type monopole antennas [3], one-sided directional slot antennas $[4,5]$, and omnidirectional slot antennas [6]. UWB has low power consumption, low power output, and high range resolution, which are the reasons for the expected use of UWB in indoor position detection in wireless sensor network systems [7]. In this application, it is conceivable that an antenna can be set at various places such as a wall, a pillar, and a human body; thus, flexibility is required for an antenna [8]. Moreover, it is profitable to use circularly polarized antennas, which do not require the arrangement of the antenna directions $[9,10]$.

(Marked 2-2) UWB is divided into the low band (3.4-4.8 GHz) and the high band (7.25-10.25 GHz) in Japan because interference from 5-GHz-band wireless LAN (IEEE 802.11a) systems is a serious problem. Moreover, in the low band, there is interference from other mobile applications. Therefore, the high band attracts attention. Thus, in high-band UWB applications, the device size, including the antenna, becomes small. 
In this paper, a circularly polarized slot antenna on a flexible substrate for UWB high-band (7.25-10.25 GHz) applications is proposed [11]. Generating a circularly polarized wave in the UWB high-band, our proposed antenna has two slots that are crossed perpendicularly. The antenna has many parameters, and each parameter affects the impedance matching and axial ratio. Additionally, we studied the flexibility of the proposed antenna by bending the antennas and by measuring the characteristics near a human body. For the measurement near a human body, we measured the antenna characteristics under two situations considering body area network applications. In one situation, the antenna is placed on the skin of the arm directly. In the other situation, the antenna is placed on the clothes. (Marked 2-2) Section II and III describe the layout and parameter and simulation results of our proposed antenna. In section IV, the experimental results are presented, and a summary and conclusions are provided in Section VI.

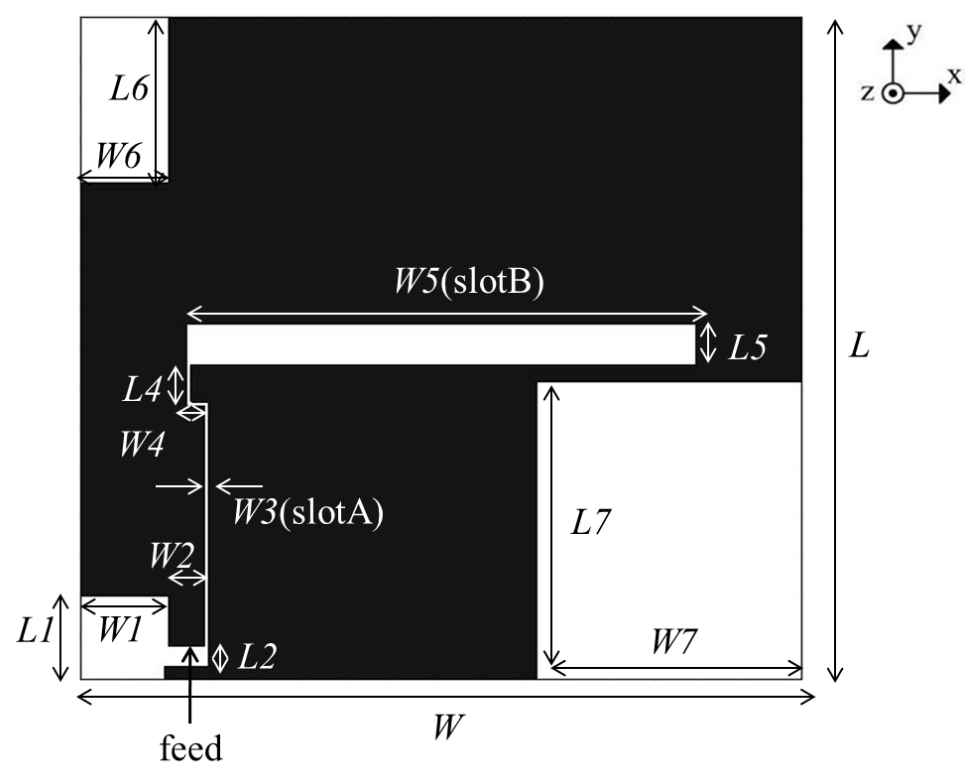

(a) Top view (x-y plane)

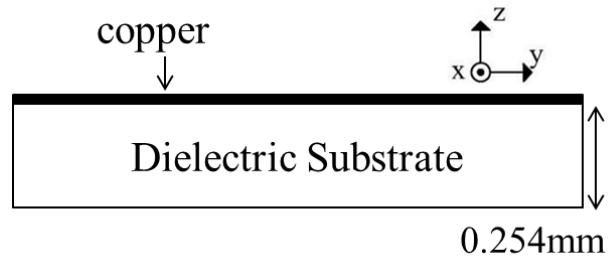

(b) Cross sectional view (y-z plane)

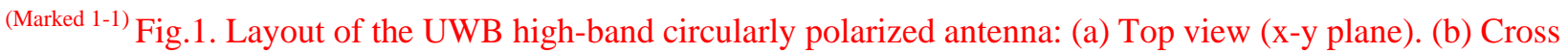
sectional view (y-z plane)."

\section{Antenna Design}

Fig. 1 shows the configuration of the proposed circularly polarized planar antenna for UWB high-band systems and the cross section of the substrate. The values of all the parameters of the proposed antenna are listed in TABLE I. This antenna is on a substrate with flexible characteristics. The substrate has a dielectric constant $\left(\varepsilon_{\mathrm{r}}\right)$ of 3.5 and a loss $\operatorname{tangent}(\tan \delta)$ of 0.0015. The thicknesses of the dielectric and metal $(\mathrm{Cu})$ layer are $0.254 \mathrm{~mm}$ and $20 \mu \mathrm{m}$, respectively. The $+\mathrm{y}$-direction slot (slot $A$ ) and $+\mathrm{x}$-direction slot (slot $B$ ) generate circularly polarized waves, and the lower right slot and the upper left slot are useful for impedance matching. An RF signal is generated through the surface-mounted connector at the feed point. 
TABLE 1. Value of Each Parameter of the Proposed Antenna

\begin{tabular}{|c|c|c|c|c|c|c|c|}
\hline$W$ & $W 1$ & $W 2$ & $W 3$ & $W 4$ & $W 5$ & $W 6$ & $W 7$ \\
\hline 16.3 & 2.0 & 0.5 & 0.1 & 0.4 & 12.0 & 2.0 & 6.0 \\
\hline$L$ & $L 1$ & $L 2$ & $L 3$ & $L 4$ & $L 5$ & $L 6$ & $L 7$ \\
\hline 16.0 & 2.0 & 0.5 & 5.8 & 1.0 & 1.0 & 4.0 & 7.2 \\
\hline
\end{tabular}

\section{Antenna Characteristics}

Fig. 2(a) and 2(b) shows the frequency dependence of the reflection coefficient $\left(\mathrm{S}_{11}\right)$ and an axial ratio $(A R)$ with different values of length $L$. Generally, a circularly polarized antenna has an $A R$ of less than $3 \mathrm{~dB}$. As shown in Fig. 2(a), the resonance frequency does not change when $L$ changes; thus, the impedance bandwidth $S_{11}$ is lower than $-10 \mathrm{~dB}$ and shows almost no change. However, the $A R$ is significantly changed by changing $L$, as shown in Fig. 2(b), and the optimal size of $L$ is $16 \mathrm{~mm}$. In this case, the simulated $A R$ bandwidth of the proposed antenna is $4.26 \mathrm{GHz}$ from $7.06 \mathrm{GHz}$ to $11.32 \mathrm{GHz}$, which satisfies the UWB high-band requirements.

Fig. 3(a) and 3(b) shows the frequency dependence of $S_{11}$ and an $A R$ with different values of length $L 7$. As shown in Fig. 3(a), the resonance frequency follows the variation of $L 7$ closely. However, the value of the $S_{11}$ is changed, implying that impedance matching is realized by changing the length of $L 7$, and $L 7$ is determined as $7.2 \mathrm{~mm}$. In this case, $A R$ satisfies the UWB high-band regulation, as shown in Fig. 3(b).

Fig. 4 shows the simulated radiation patterns of the proposed antenna on the $y-z$ plane at (a) $7.5 \mathrm{GHz}$, (b) $8.5 \mathrm{GHz}$, and (c) 9.5 GHz. The proposed antenna radiates a left-handed circular polarization (LHCP) in the $+\mathrm{z}$-axis direction and a right-handed circular polarization (RHCP) in the-z-direction. The realized gain is $2.0 \mathrm{dBic}$ at $7.5 \mathrm{GHz}, 3.2 \mathrm{dBic}$ at $8.5 \mathrm{GHz}$, and $3.2 \mathrm{dBic}$ at $9.5 \mathrm{GHz}$. The beamwidth for the $+\mathrm{z}$-direction becomes narrow as the frequency increases; however, the radiation patterns are similar in the UWB high band.

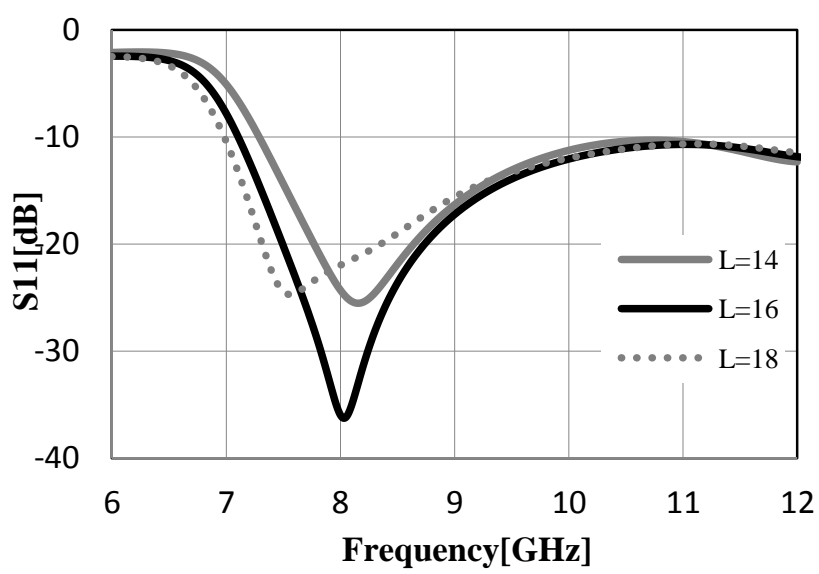

(a) Reflection coefficient $\left(\mathrm{S}_{11}\right)$ 


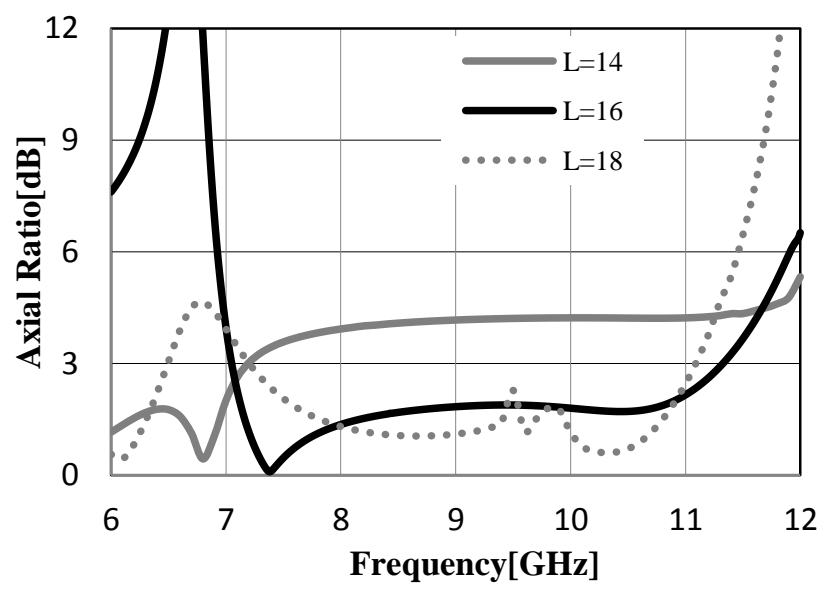

(b) Axial ratio

Fig. 2. Frequency characteristics of the reflection coefficient and axial ratio with variation of $L$.

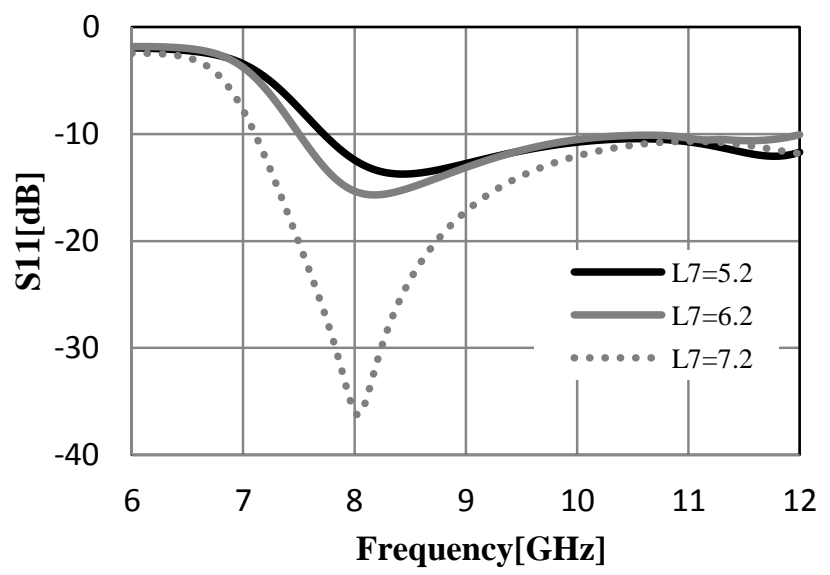

(a) Reflection coefficient $\left(\mathrm{S}_{11}\right)$

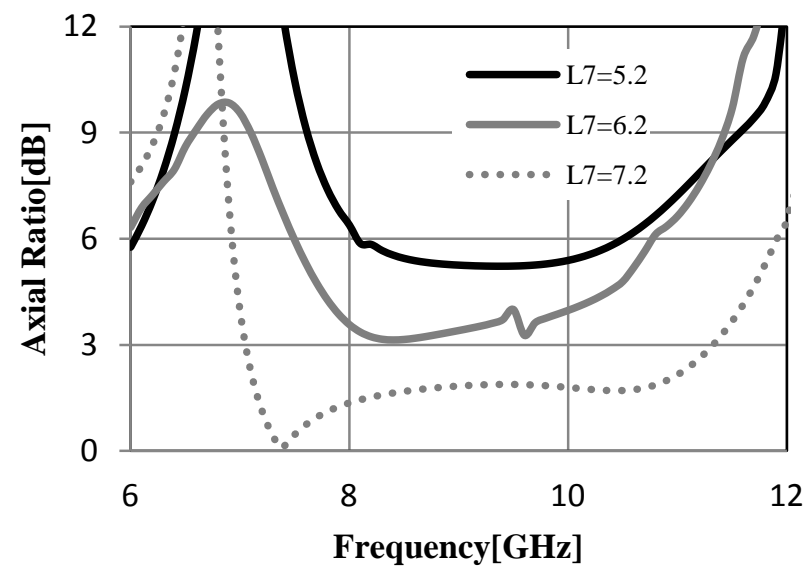

(b) Axial ratio

Fig. 3. Frequency characteristics of the reflection coefficient and axial ratio with variation of $L 7$. 


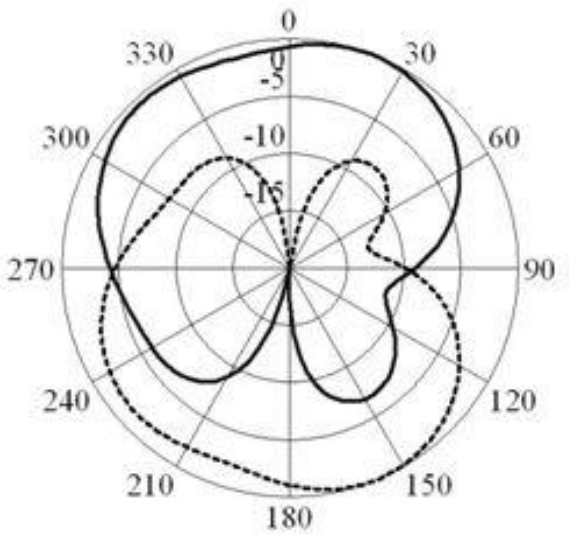

(a) $7.5 \mathrm{GHz}$

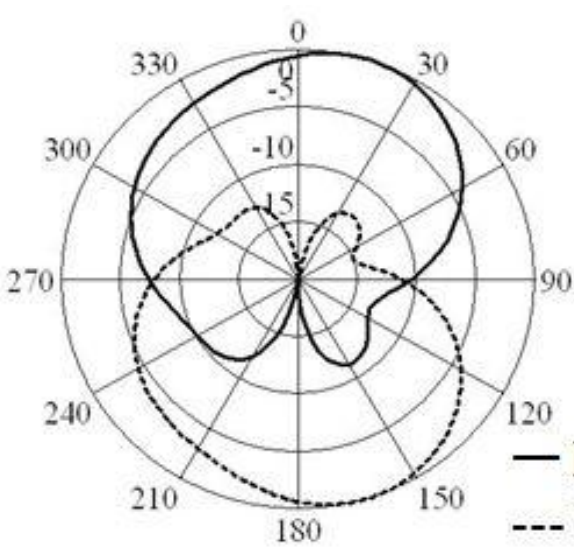

(b) $8.5 \mathrm{GHz}$

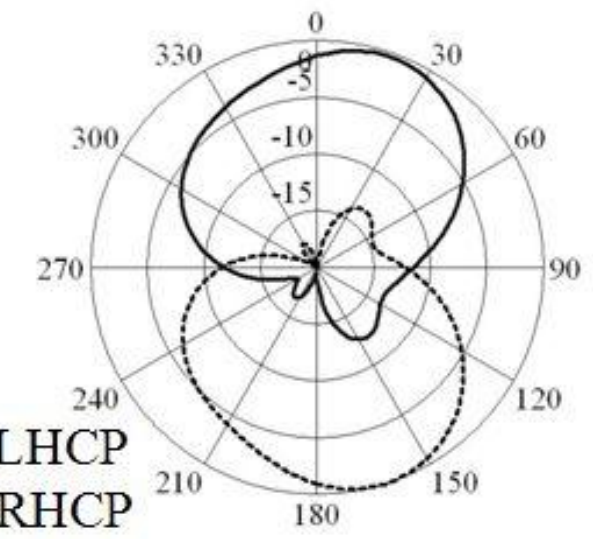

(c) $9.5 \mathrm{GHz}$

Fig. 4. Simulated radiation patterns (y-z plane) of the proposed antenna at (a) $7.5 \mathrm{GHz}$, (b) $8.5 \mathrm{GHz}$, and (c) 9.5

$\mathrm{GHz}$.

Our proposed antenna is designed to be set on various places such as a wall, a pillar, and a human body; thus, flexibility is tested in this study.

Fig. 5(a) shows the cross section of the proposed antenna (x-z plane) under bending. In the figure, $A$ is the bending angle. Fig. 5(b) and 5(c) show the frequency dependence of $S_{11}$ and an $A R$ with a varying bending angle $A$. As shown in Fig. 5(b), the resonance frequency is slightly shifted lower; however, the -10-dB bandwidth of $S_{11}$ is almost identical, and the bandwidth of the proposed antenna is $5.60 \mathrm{GHz}$ from $7.11 \mathrm{GHz}$ to $12.71 \mathrm{GHz}$, which satisfies the UWB high-band application requirements. On the other hand, the $A R$ bandwidth becomes narrow as the $A$ increases, and the simulated 3-dB $A R$ bandwidth is $3.14 \mathrm{GHz}$ from $7.24 \mathrm{GHz}$ to $10.40 \mathrm{GHz}\left(A=10^{\circ}\right)$ and $2.88 \mathrm{GHz}$ from $7.25 \mathrm{GHz}$ to $10.13 \mathrm{GHz}\left(A=20^{\circ}\right)$, as shown in Fig. 5(c). However, the $A R$ of this antenna satisfies the UWB high-band application requirements if $A=20^{\circ}$. Therefore, our proposed antenna can operate as a circularly polarized wideband antenna even when the antenna is bent. (Marked 2-3) Fig. 6(a) and 6(b) shows the frequency characteristics of the LHCP gain and RHCP gain at +z-direction. The gain difference is more than $15 \mathrm{~dB}$ in the pass band. 


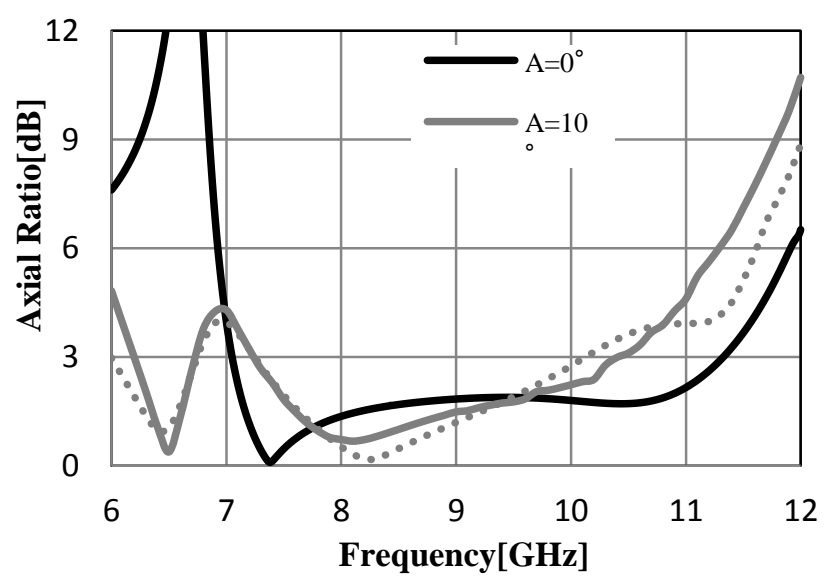

(c) Axial ratio

Fig. 5. Cross section of the proposed antenna (a), frequency characteristics of the reflection coefficient (b), and axial ratio (c) with variation of the bending angle $A$. 


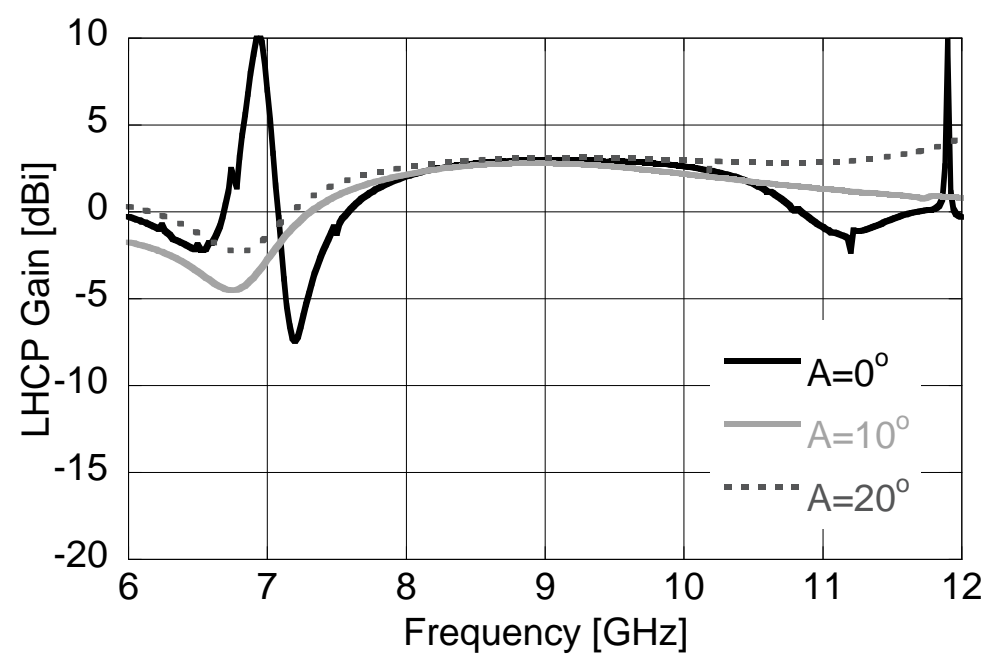

(a) LHCP gain

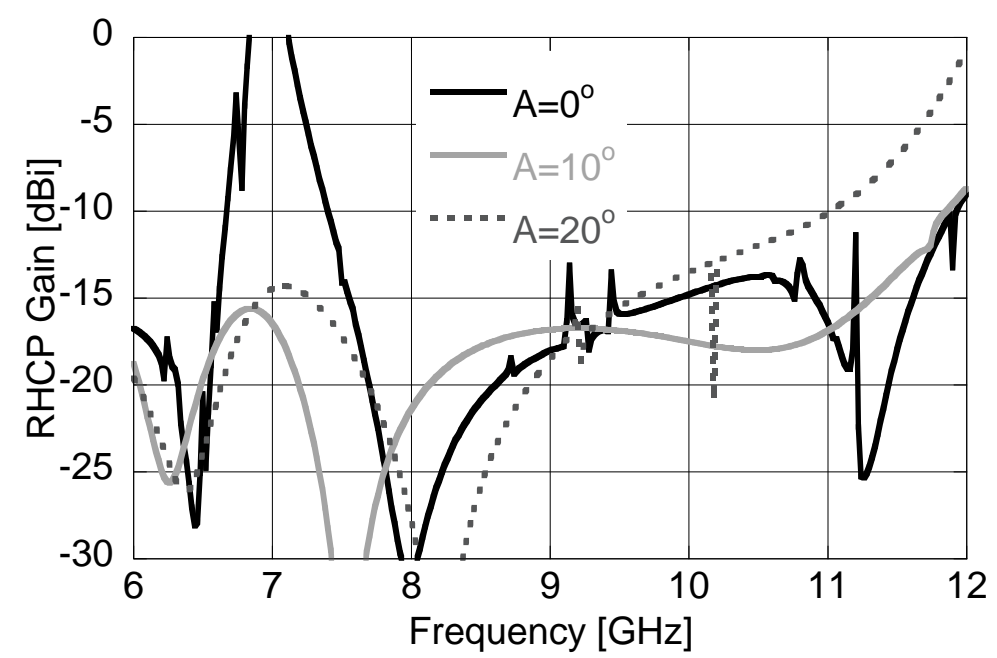

(b) RHCP gain

${ }^{\text {(Marked } 2-3)}$ Fig. 6. Frequency characteristics of the LHCP gain (a) and RHCP gain (b) at + z-direction.

Next, our proposed antenna is assumed to be placed on the human body for a body area network application. Because the human body is a lossy medium and has a high dielectric constant, the propagating wave is highly attenuated [12, 13]. To understand the complex electromagnetic characteristics of the human body and their impact on antenna parameters, a simulation model is shown in Fig. 7, where this antenna is placed $d \mathrm{~mm}$ away from the tissue model. In this simulation, we approximated a human body with a single-layer muscle model. The muscle model has a dielectric constant $\varepsilon_{\mathrm{r}}$ of 43.8 , a loss $\operatorname{tangent} \tan \delta$ of 0.488 , and a conductivity $\sigma$ of 10.1 [14]. The size of the muscle model is $30 \mathrm{~mm} \times 30 \mathrm{~mm} \times 10 \mathrm{~mm}$.

Fig. 8 shows the relationship between the distance of the antenna from the muscle model $(d)$ and the antenna gain for the +z-direction at $7.5 \mathrm{GHz}, 8.5 \mathrm{GHz}$, and $9.5 \mathrm{GHz}$. The antenna gain increases proportionally with the logarithm of $d$ and is saturated around $d=5 \mathrm{~mm}$, with a gain of approximately $5 \mathrm{dBic}$. 


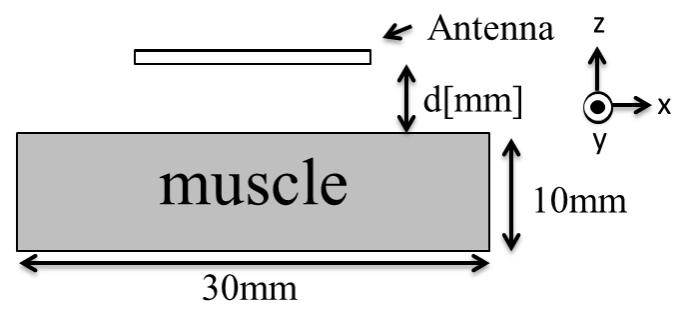

Fig. 7. Situation setup of the tissue model.

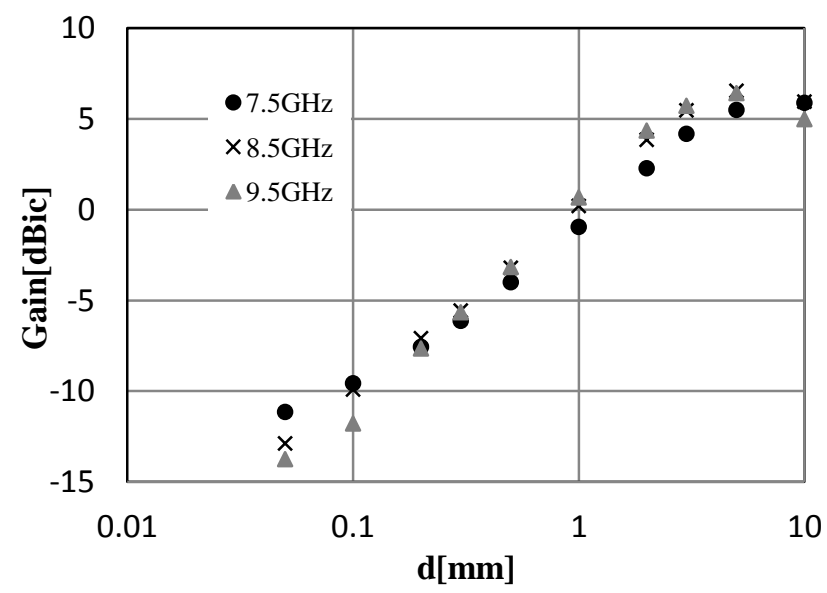

Fig. 8. Relationship between the distance $(d)$ of the antenna from muscle model and antenna gain at 7.5, 8.5, and $9.5 \mathrm{GHz}$.

\section{EXPERIMENTAL RESUlts}

The proposed circularly polarized antenna for a UWB high-band application is fabricated on a flexible substrate (Taconic, RF-35A2). Fig. 9 shows images of a planar antenna and a bent antenna.

Fig. 10 shows the simulated and experimental results of the reflection coefficient of the proposed antenna. The measured $\mathrm{S}_{11}$ characteristics have similar properties in the simulation. However, some unexpected resonances cause residual effects of the solder and connector at the feed point. The measured value of $S_{11}$ is less than $-8 \mathrm{~dB}$ in the UWB high band.

Fig. 11 shows the measured and simulated radiation patterns of the proposed antenna at (a) $7.5 \mathrm{GHz}$, (b) $8.5 \mathrm{GHz}$, and (c) 9.5 GHz. The measured radiation patterns are similar to those in the simulation. For the LHCP, radiation toward the $+\mathrm{z}$-direction is generated. 


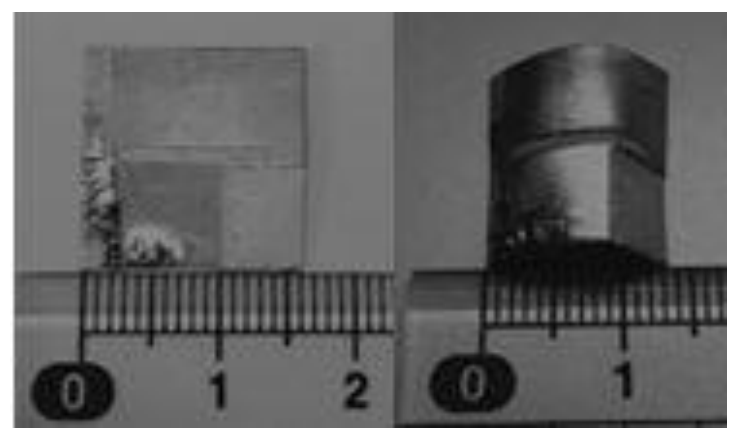

Fig. 9. Images of the proposed antenna while flat and bent.

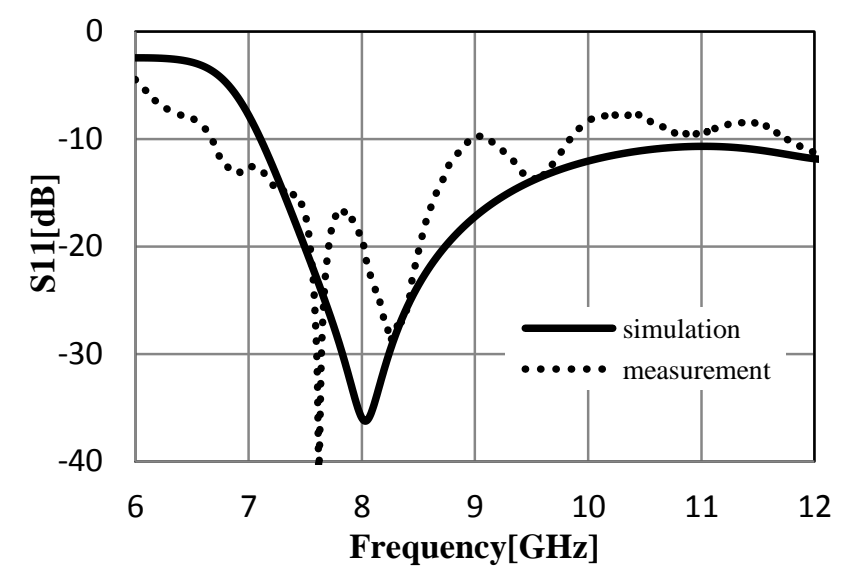

Fig. 10. Measured reflection coefficient of the proposed antenna.

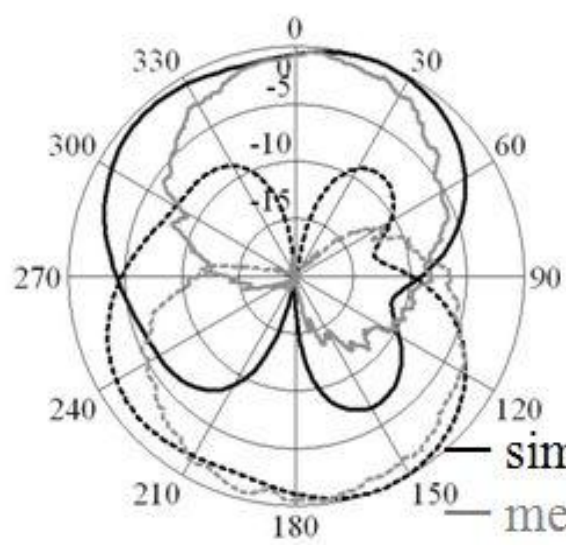

(a) $7.5 \mathrm{GHz}$

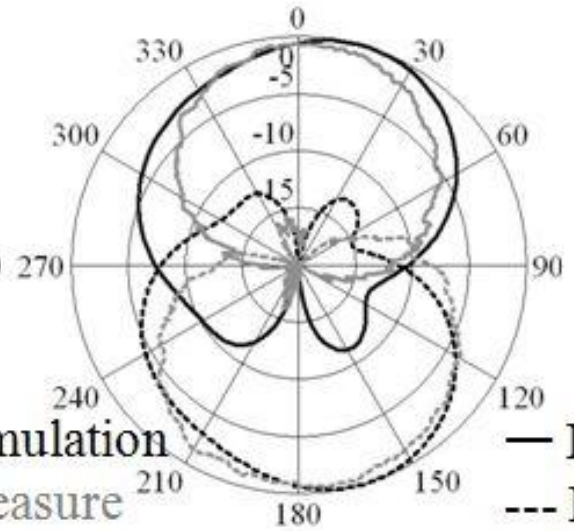

(b) $8.5 \mathrm{GHz}$

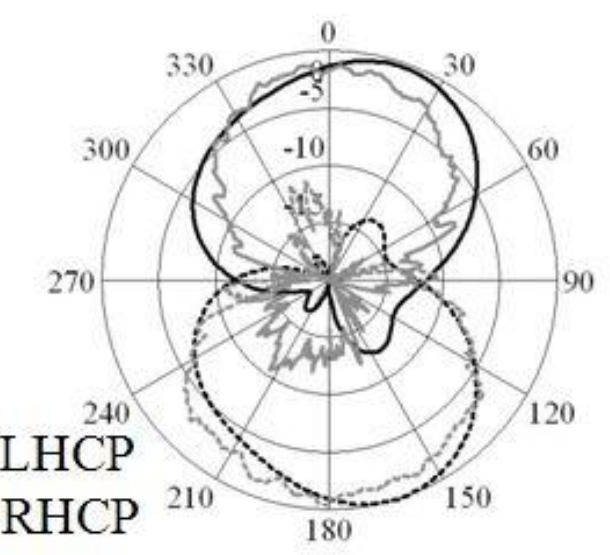

(c) $9.5 \mathrm{GHz}$

Fig. 11. Measured radiation patterns (y-z plane) of the proposed antenna at (a) $7.5 \mathrm{GHz}$, (b) $8.5 \mathrm{GHz}$, and (c) 9.5 $\mathrm{GHz}$.

Fig. 12 shows the experimental setup for the gain measurement near a human body. Fig. 12(a) shows a case where the antenna is placed on the skin of the arm directly. Fig. 12(b) shows a case where the antenna is placed on clothes.

Fig. 13(a) and 13(b) shows the measured frequency dependence of $S_{11}$ and the antenna gain in the +z-direction, respectively. In the figure, "in air" implies that the antenna is in free space. As shown in Fig. 13(a), $S_{11}$ has similar properties in all the tested situations and maintains its frequency bandwidth for the UWB high-band application.

As shown in Fig. 13 (b), the antenna gain shows significant differences, especially when the proposed antenna is placed on 
skin, and the antenna gain is $15-20 \mathrm{~dB}$ smaller than that of the antenna in free space. The measured gain agrees with the simulation results, as shown in Fig. 8. On the other hand, the gain of the antenna on the clothes is similar to that in free space.

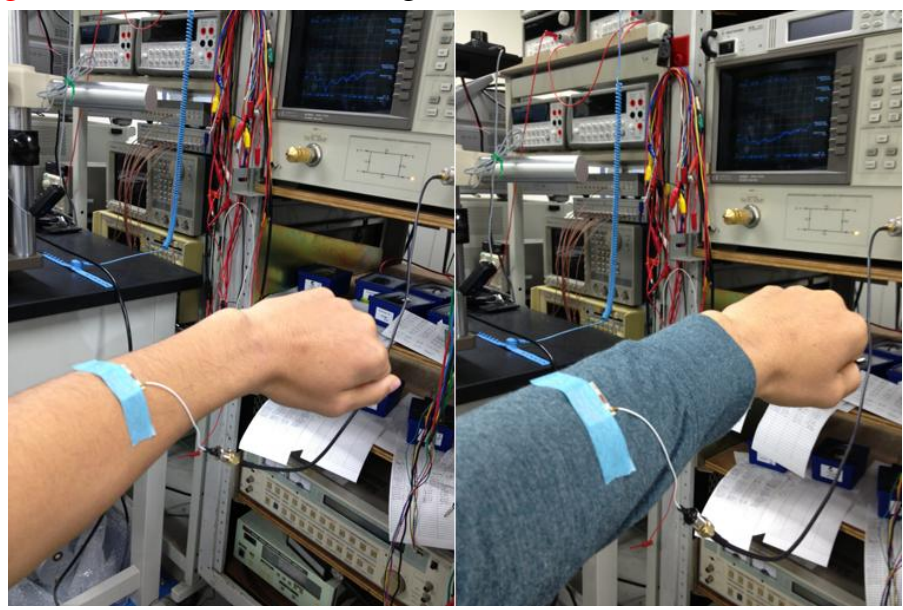

$\begin{array}{ll}\text { (a) Antenna on skin. } & \text { (b) Antenna on clothes. }\end{array}$

Fig. 12. Measured characteristics of the proposed antenna near a human body.

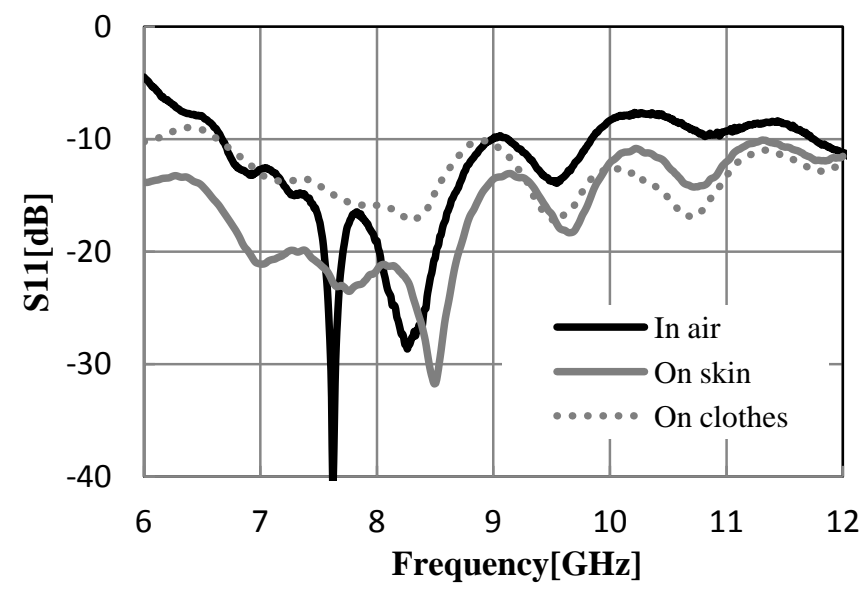

(a) Reflection coefficient (S11)

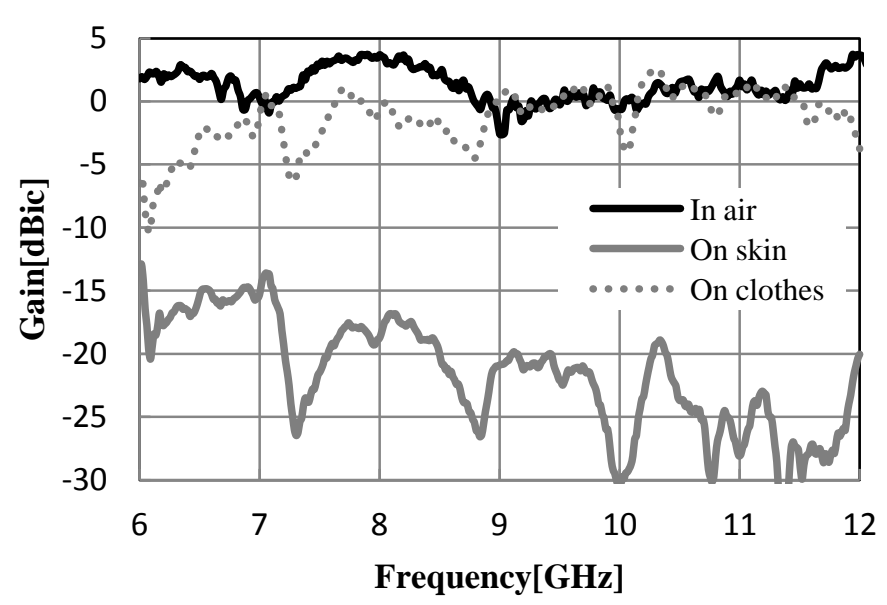

(b) Antenna gain

Fig. 13. Measured reflection coefficient (a) and the antenna gain (b) of the proposed antenna near a human body. 


\section{CONCLUSION}

The design of the circularly polarized antenna on a flexible substrate for UWB high-band (7.25-10.25 GHz) applications is proposed in this paper. The size of the proposed antenna is $16.3 \mathrm{~mm} \times 16 \mathrm{~mm} \times 0.254 \mathrm{~mm}$, which is almost a square shape, and this antenna is realized on a flexible and thin $(0.254 \mathrm{~mm})$ substrate. To generate a circularly polarized wave in wideband, we utilized two slots that were crossed perpendicularly. The experimental results of $S_{11}$ yielded a value less than $-8 \mathrm{~dB}$ in the UWB high band, and the measured $A R$ was less than $3 \mathrm{~dB}$, which is suitable for UWB high-band applications. We also confirmed the antenna characteristics under bending and near a human body. The antenna gain depends on the distance from the body; when the antenna distance from the body is larger than $5 \mathrm{~mm}$, the gain is approximately $5 \mathrm{dBic}$. The measured characteristics of the proposed antenna on a human body agree with the simulation results.

\section{ACKNOWLEDGMent}

(Marked 3-1) This work was partly supported by a Grant-in-Aid for KAKENHI (Kiban-C) and Core Research for Evolutional Science and Technology (CREST) in Japan Science and Technology Agency, and Strategic Information and Communications R\&D Promotion Programme (SCOPE) in Ministry of Internal Affairs and Communications.

\section{REFERENCES}

[1] M. Kim and J. Takada, "Characterization of Wireless On-Body Channel under Specific Action Scenarios at Sub-GHz Bands," IEEE Trans. Antennas Propag., Vol. 60, pp. 5364-5372, 2012.

[2] J. Li, Z. Zeng, J. Sun, and F. Liu, "Through-Wall Detection of Human Being's Movement by UWB Radar," IEEE Geoscience and Remote Sensing Letters, Vol. 9, No. 6, pp. 1079-1083, 2012.

[3] X. C. Yin, C. L. Ruan, C. Y. Ding, and J. H. Chu, "A Planar U Type Monopole Antenna For UWB Applications," Progress In Electromagnetics Research Letters, Vol. 2, pp. 1-10, 2008.

[4] S. Ijiguchi, H. Kanaya, D. Kanemoto, K. Yoshida, P. K. Pokharel, K. Yoshitomi, A. Ishikawa, S. Fukagawa, and A. Tahira, "Development of One-Sided Directional Printed Slot Antenna for High-Band UWB systems," IEEE Antennas Propag. Soc. Int. Symp., pp. 1474-1477, 2011.

[5] L. Yang, E. Tammam, K. Yoshitomi, S. Ijiguchi, H. Kanaya, K. Yoshida, A. Ishikawa, S. Fukagawa, N. Kodama, and A. Tahira, "CPW-Fed Slot Antenna for UWB Short-Range Impulse Radar Systems," IEICE Electronics Express, Vol. 9, No. 20, pp. 1604-1610, 2012.

[6] I. T. Tang, D. B. Lin, G. H. Liou, J. H. Horng, and C. M. Li, "A Compact Slot UWB Antenna with CPW-Fed," IEEE Antennas Propag. Soc. Int. Symp., pp. 5143-5146, 2007.

[7] G. Shingu, K. Takizawa, and T. Ikegami, "Human Body Detection Using UWB Radars in an Indoor Environment," IEICE Technical Report, WBS2007-50, pp. 19-24, 2007.

[8] W. S. Kang, H. K. Yoon, and Y. J. Yoon, "Flexible Monopole Antennas for UWB Systems," IEICE Technical Report, AP2007-159, pp. 213-218. 
[9] J. Pourahmadazar, C. Ghobadi, J. Nourinia, N. Felegari, and H. Shirzad, "Broadband CPW-Fed Circularly Polarized Square Slot Antenna With Inverted-L Strips for UWB Applications," IEEE Antennas Wireless Propag. Lett, pp. 369-372, 2011.

[10] Q. Chen, H. L. Zheng, T. Quen, and X. Li, "Broadband CPW-Fed Circularly Polarized Antenna With Equiangular Tapered Shaped Feedline for Ultra Wideband,” Progress In Electromagnetics Research C, Vol. 26, pp. 83-95, 2012.

[11] K. Fujtia, D. Kanemoto, K. Yoshitomi, K. Yoshida, and H. Kanaya, "UWB Circularly Polarized Planar Antenna on Flexible Substrate," Proc. IEEE MTT-S International Microwave Workshop Series on RF and Wireless Technologies for Biomedical and Healthcare Applications, TP17, USB, pp.1-3, 2013.

[12] IEEE 802.15 WPAN Task Group 6 (TG6) Body Area Networks, IEEE Standard 802.15.6, 2011.

[13] Z. N. Chen, “Antennas for Portable Devices,” John Wiley \& Sons Ltd, 2007.

[14] C. Gabriel, "Compilation of the Dielectric Properties of Body Tissues at RF and Microwave Frequencies," AL/OE-TR-1996-0037 Rep., 1996. 